\title{
Anemia and Dietary Behaviors among Young Adults in Riyadh, Saudi Arabia
}

Fakhr AlAyoubi ${ }^{1}$; Mohamed Rashrash ${ }^{2}$; Yasmin Elsharawy ${ }^{1}$; Samha Alayoubi ${ }^{3}$; Wed A. Alayoubi ${ }^{4}$; Nouf Alnumair ${ }^{4}$ Tarek Owaidah ${ }^{4}$

${ }^{1}$ College of Pharmacy, King Saud University - Riyadh, Saudi Arabia

${ }^{2}$ Department of Pharmaceutical \& Administrative Sciences, University of Charleston School of Pharmacy, West Virginia

${ }^{3}$ King Fahad Cardiac Center, College of Medicine, King Saud University Medical City

${ }^{4}$ King Faisal Specialist Hospital and Research Center

\begin{abstract}
Objective: The study sought to assess the prevalence and the risk factors associated with anemia among male and female young adults in (Riyadh city, Saudi Arabia).

Methods: A cross-sectional study was conducted at King Saud University and Alfaisal University in September 2016 among young adults aged 18 to 28 years old. Data were collected using an interview questionnaire. Additionally, the respondents were evaluated clinically and via laboratory testing for anemia.

Results: Our study population showed a higher percentage of men as compared to women participants. About half of our study sample had a lightly active lifestyle, and more than one-third of the study participants were overweight (34.7\%). The average age of the respondents was $22.08 \pm 1.98$ years. The only factor significantly associated with anemia was gender, in that female gender showed a positive association with anemia.

Conclusion: The most explicit risk factor for anemia among Saudi individuals of college and young professional ages was the female gender. Dietary lifestyle, heavy menstruation, pregnancy, and intake of non-steroidal anti-inflammatory drugs were additional important risk factors among these individuals, but they were statistically not significant.
\end{abstract}

\section{Introduction}

According to the World Health Organization (WHO), about 800 million children and women were affected by anemia around the world in 2011 (1). The same WHO report also stated that the prevalence of anemia among pregnant women was $38.2 \%$ and for all childbearing age women was $29.4 \%$. The report estimated that the peak prevalence of anemia was among children $(42.6 \%)$, and the least was among non-pregnant women $(29.0 \%)$.

Another study mentioned that more than 2 billion people suffer from anemia worldwide (2). Considering Arab countries, the same study reported that the prevalence of Iron-deficiency anemia (IDA) was more than $70 \%$ among newborn children.

Iron-deficiency anemia results when either dietary intake does not meet the body's requirements of iron or when there is chronic external (non-resorptive) blood loss. The diagnosis of Iron Deficiency Anemia is confirmed by the findings of low iron stores and a hemoglobin level that is two standard deviations below what is normal according to age and sex. The prevalence of IDA among schoolgirls aged 7 to 14 years old in Riyadh was about $26 \%$ (3)

\section{Corresponding author:}

Mohamed Rashrash, BPharm, MPharm, PhD

Assistant Professor Pharmaceutical \& Administrative Sciences University of Charleston School of Pharmacy

2300 MacCorkle Avenue SE, Charleston, West Virginia 25304

Email: mohamedrashrash@cuwv.edu; Phone: +13174918745
Maternal anemia increases the risk of mortality and morbidities among the mothers and their children such, as stillbirth, premature, and low birth weight babies. In developing countries, iron deficiency anemia is responsible for $20 \%$ of perinatal and $10 \%$ of maternal mortality (4). Each $10 \mathrm{~g} / \mathrm{l}$ increase in maternal hemoglobin level will lead to $30 \%$ decrease in maternal mortality (5)

Anemia is a multi-factorial sickness and preserves the role of both the risk factor and the outcome of illness (6). There is a variety of changeable and unchangeable factors impacting anemia, either solo or in connection with one another. These may include socio-demographic factors such as race, gender, or age, or other factors including but not limited to diet, gynecological/obstetric history, and genetics (6). Also, anemia is usually associated with chronic and malignant diseases such as tumors, hypothyroidism, hypertension, chronic renal disease, rheumatism, and heart failure (7)

Separately, precise risk elements might comprise iron status, including worm invasion, frequent pregnancies, bleeding, a history of diseases such as hemorrhoids and peptic ulcer, or the use of medications such as aspirin/non-steroidal antiinflammatory agents (NSAIDs) (6).

The role of dietary intake of food inhibitors such as coffee and tea or food enhancers such as meat or vitamin C on the absorption of iron and the body's iron stores remains controversial, and their effect on anemia is also still questionable $(8,9)$. 
The consequences of anemia are various. In pregnant women, this condition affects either an embryo's physical or mental growth; in children, it influences cognitive and development growth; in adults, it reduces physical exertion capability, and in elderly people, it can adversely affect the overall quality of life (10-17). In severe circumstances, it may cause maternal and/or newborn death (13-16).

Data on anemia in Saudi Arabia are currently scarce (18-21). A case-control study was conducted by AlQuaiz et al. at all primary health care clinics of King Khalid University Hospital in Riyadh to determine the risk factors for IDA, with results suggesting that important risk factors for IDA among Saudi women of childbearing age include dietary habits, menorrhagia, and a history of ingestion of NSAIDs or antacids. Their study further concluded that nutritional and medicationtaking behaviors such as the consumption of low meat or juice or the use of antacids or NSAIDs were highly associated with anemia in Saudi females of the fertile age range (21).

The American Academy of Family Physicians, United States Preventive Services Task Force, and United States Centers for Disease Control and Prevention recommend routine screening for IDA in asymptomatic pregnant women be completed. The American College of Obstetricians and Gynecologists also recommends screening for anemia and the implementation of iron therapy if IDA is confirmed. Anemia in pregnancy is confirmed with a hemoglobin level of less than $11 \mathrm{~g} / \mathrm{dL}$ (110 $\mathrm{g} / \mathrm{L}$ ) in the first or third trimesters or less than $10.5 \mathrm{~g} / \mathrm{dL}$ (105 $\mathrm{g} / \mathrm{L}$ ) in the second trimester. A maternal hemoglobin level of less than $6 \mathrm{~g} / \mathrm{dL}(60 \mathrm{~g} / \mathrm{L})$ has been associated with poor fetal outcomes, including death (22). Low birth weight, a history of prematurity, exposure to lead, exclusive breastfeeding beyond four months of life, and weaning to whole milk and complementary foods without including iron-fortified foods are risk factors for IDA in children. As such, all children at the age of one year should undergo hemoglobin screening and be evaluated for risk factors for iron deficiency (23).

Iron is not absorbed in the stomach and is instead absorbed best from the distal duodenum and proximal jejunum. Prolonged achlorhydria may produce iron deficiency because acidic conditions are required to release ferric iron from food. Subsequently, it is chelated with mucins and other substances (e.g., amino acids, sugars, amino acids, amides) to keep it soluble and available for absorption in the more alkaline duodenum. It is crucial to take iron either two hours before or four hours after the ingestion of antacids. Also, the consumption of starch and clay, the latter of which is more common in parts of Africa and the Middle East, and can lead to mal-absorption of iron and possibly IDA (24).

IDA is a worldwide health problem. It can occur at all stages of the life cycle but is more prevalent in women and young children due to pregnancy and menstrual blood loss (25). In 2002, iron deficiency was thought to be the most common cause of anemia globally, although other conditions such as folate, vitamin B12 and vitamin A deficiencies, chronic inflammation, parasitic infections, and inherited disorders can also all cause anemia (25).

Iron deficiency is the most common cause of microcytic anemia, although up to $40 \%$ of patients with IDA will have normocytic erythrocytes. IDA can reduce work productivity in affected adults and impact both motor and mental development in children and adolescents. Some evidence has shown that iron deficiency without anemia may affect the cognitive performance, behavior, and physical growth of infants and preschool and school-aged children and can cause fatigue in adult women (17). Therefore, the early diagnosis and management of the disease and the causes of iron deficiency are extremely important in order to improve overall health outcomes.

Hence, our study aims to determine the prevalence and risk factors for iron deficiency and IDA among different age groups in Riyadh, Saudi Arabia. Knowing the risk factors of this disease will assist with developing more efficient plans to manage this ailment.

\section{Materials and Methods}

A cross-sectional study was conducted at King Saud University and Alfaisal University, Riyadh, Saudi Arabia, in September 2016. The IRB approval was granted in May 2016 from Institutional Review Board, King Saud University Medical City. The inclusion criteria were age between 18 and 28 years, female respondents not currently pregnant, able to understand and speak Arabic and residency in Riyadh.

Data were collected using a specifically structured interview questionnaire to satisfy the study objectives. Convenient sampling was used, and interviews were conducted and followed up by the authors of this study in different locations in both universities. The instrument covered four sections, as follows: demographic information such as age, sex, and education; dietary and lifestyle; anemia symptoms; and general health status.

Study participants also were evaluated clinically and via laboratory testing for anemia by using a point-of-care instrument .Written informed consent was taken, and a sample of $5 \mathrm{~mL}$ of venous blood was drawn to evaluate the hemoglobin, red cell indices, and hematocrit status in each study subject. Blood samples were collected, and results were obtained, excluding from those already on iron supplementation. The cutoff value for the determination of anemia was defined as a blood hemoglobin concentration of less than $12 \mathrm{~g} / \mathrm{dL}$. Descriptive and inferential statistical analyses were conducted using the Statistical Package for the Social Sciences version 24 software program (IBM Corp., Armonk, NY, USA). Chi-square and logistic regression analyses were used to assess any association between the dependent 
and independent variables. The estimation of odds ratio (OR) was at $95 \%$ confidence interval $(\mathrm{Cl})$. The dependent variable was the diagnosis with anemia, while the independent variables included in the analyses were demographic factors such as age, gender, education, and health-related factors such as disease, medication, blood donation, family history of anemia in addition to dietary habits, and symptom checker.

\section{RESULTS}

All respondents were in the age range of 18 to 28 years (mean: $22.08 \pm 1.98$ years), as shown in Table 1 . Males were dominant in our study (54.3\%). Additionally, approximately one-third of the respondents had a bachelor's degree (31.8\%). In total, about $80 \%$ of our study participants were students, and their economic status was either good or very good. Nearly half of our sample had a lightly active lifestyle (48.6\%). Almost onethird of subjects were smokers (30.1\%), but none reported drinking alcohol with any frequency. More than one-third of the cases were overweight (34.7\%). No significant association was found with socio-demographic variables. The only factor associated with anemia was gender, as female gender showed a positive association with anemia prevalence (OR: 4.18; $\mathrm{p}<.01)$

Table 1 - Socio-demographic characteristics of respondents ( $N=173$ )

\begin{tabular}{|c|c|c|c|c|c|}
\hline Character & & $\mathrm{n}$ (Percent) & Odds Ratio & Chi-square & P-Value \\
\hline Age & & & .993 & NA & $>.05$ \\
\hline \multirow[t]{2}{*}{ Gender } & Male & $94(54.3 \%)$ & 4.18 & 7.843 & $.008^{*}$ \\
\hline & Female & 79(45.7\%) & & & \\
\hline \multirow[t]{3}{*}{ Occupation } & Employed & $22(12.7 \%)$ & & 5.736 & $>.05$ \\
\hline & Unemployed & $13(7.5 \%)$ & & & \\
\hline & Student & $138(79.8 \%)$ & & & \\
\hline \multirow[t]{2}{*}{ Education } & Secondary School & $118(68.2 \%)$ & & .703 & $>.05$ \\
\hline & Bachelor & $55(31.8 \%)$ & & & \\
\hline \multirow[t]{5}{*}{ Economic Status } & Very Good & $64(37.0 \%)$ & & 2.515 & $>.05$ \\
\hline & Good & $69(39.9 \%)$ & & & \\
\hline & Average & $30(17.3 \%)$ & & & \\
\hline & Enough & $8(4.6 \%)$ & & & \\
\hline & Not Enough & $2(1.2 \%)$ & & & \\
\hline \multirow[t]{2}{*}{ Living altitude } & High altitude & $14(8.1 \%)$ & & 1.991 & $>.05$ \\
\hline & No & $159(91.9 \%)$ & & & \\
\hline \multirow[t]{4}{*}{ Activity } & Sedentary & $41(23.7 \%)$ & & 1.847 & $>.05$ \\
\hline & Lightly Active & $84(48.6 \%)$ & & & \\
\hline & Moderately Active & $37(21.4 \%)$ & & & \\
\hline & Very Active & $11(6.4 \%)$ & & & \\
\hline \multirow[t]{2}{*}{ Smoking } & Yes & $52(30.1 \%)$ & & 1.088 & $>.05$ \\
\hline & No & $121(69.9 \%)$ & & & \\
\hline \multirow[t]{2}{*}{ Alcohol } & Yes & $2(1.20 \%)$ & & .264 & $>.05$ \\
\hline & No & $171(98.8 \%)$ & & & \\
\hline \multirow[t]{3}{*}{ BMI } & Underweight & $8(4.6 \%)$ & & 2.094 & $>.05$ \\
\hline & Normal & $105(60.7 \%)$ & & & \\
\hline & Overweight & $60(34.7 \%)$ & & & \\
\hline
\end{tabular}

Table 2 showed that only $12 \%$ of the sample was diagnosed with anemia, and $4 \%$ had family history of Thallasemia or sickle cell anemia. Most of the patients of anemia were females (75\%). About three-quarters of our sample didn't have Consanguinity between parents (72.3\%). Approximately one-third of the subjects were frequent blood donors.

Iron supplements intake was reported by about a fifth of the respondents (18.5\%), and only $15 \%$ of our population was pregnant. Most of respondents were taking antacids and NSAIDs (76.0\%, 52.6\%, respectively). About two-thirds were using NSAIDs daily or one to six times weekly. Our sample was almost healthy and had no diseases, and the highest was the heavy period, which reported by five respondents only. 
Table 2 Descriptive and Chi-square findings of health-related factors

\begin{tabular}{|l|l|l|l|}
\hline Factor & $\mathbf{n}($ Percent) & Chi-square & P-Value \\
\hline Diagnosed With Anemia & $20(11.6 \%)$ & & \\
Yes & $153(88.4 \%)$ & & \\
No & & .053 & $>.05$ \\
\hline Family Thalassemia or Sickle Cell Anemia & $7(4.0 \%)$ & & \\
Yes & $166(96.0 \%)$ & & $>.05$ \\
No & & 3.552 & \\
\hline Consanguinity between parents & $48(27.7 \%)$ & & \\
Yes & $125(72.3 \%)$ & & \\
No & & 1.106 & \\
\hline Frequent Blood Donor & $55(31.7 \%)$ & & \\
Yes & $118(68.3 \%)$ & & \\
No & & 7.007 & \\
\hline Iron intake & $32(18.5 \%)$ & & \\
Yes & $141(81.5 \%)$ & & \\
No & & 2.625 & \\
\hline Use NSAIDs like aspirin or Paracetamol & $91(52.6 \%)$ & & \\
Yes & $82(47.4 \%)$ & & \\
No & & & \\
\hline Frequency of use NSAIDs or Paracetamol & $20(11.6 \%)$ & & \\
Daily & $43(24.9 \%)$ & & \\
4-6 times a week & $49(28.3 \%)$ & & \\
1-3 times a week & $61(35.3 \%)$ & & \\
Only when needed & & & \\
\hline Disease & $5(2.9 \%)$ & & \\
Heavy Period & $2(1.2 \%)$ & & \\
Peptic Ulcer & $2(1.2 \%)$ & & \\
Blood in Stool & $1(0.6 \%)$ & & \\
Vaginal Bleeding & $2(1.2 \%)$ & & \\
Diabetes Mellitus & $2(1.2 \%)$ & \\
Recent Injury & & \\
\hline
\end{tabular}

As shown in table 3, the most daily consumed food or drink was tea and coffee (67.6\%). The second was the chicken, which was 4 to six times weekly, as mentioned by $45.7 \%$. The third was the red meat, which reported by $35.8 \%$ consumed 2 to 3 times weekly while more than half of respondents eat fish or legumes $1-2$ times per week $59.6,50.2 \%$ consecutively.

Table3. Summary of how often respondents eat or drink different food

\begin{tabular}{lllllllll}
\hline & Red meat & Chicken & \multicolumn{1}{c}{ Fish } & Legumes & $\begin{array}{c}\text { Green } \\
\text { vegetable }\end{array}$ & $\begin{array}{c}\text { Citrus } \\
\text { fruits }\end{array}$ & $\begin{array}{c}\text { Whole } \\
\text { grain }\end{array}$ & $\begin{array}{c}\text { Tea } \\
\text { Coffee }\end{array}$ \\
\hline Daily & $11(6.4 \%)$ & $25(14.5 \%)$ & $4(2.3 \%)$ & $9(5.2 \%)$ & $34(19.7 \%)$ & $21(12.1 \%)$ & $65(37.6 \%)$ & $117(67.6 \%)$ \\
\hline $\begin{array}{l}\text { 1-2 times } \\
\text { per week }\end{array}$ & $58(33.5 \%)$ & $16(9.2 \%)$ & $103(59.6 \%)$ & $87(50.2 \%)$ & $39(22.5 \%)$ & $69(39.9 \%)$ & $25(14.5 \%)$ & $17(9.8 \%)$ \\
\hline $\begin{array}{l}\text { 2-3 times } \\
\text { per week }\end{array}$ & $62(35.8 \%)$ & $50(28.9 \%)$ & $19(11.0 \%)$ & $44(25.4 \%)$ & $43(24.9 \%)$ & $24.9 \%)$ & $39(22.5 \%)$ & $13(7.5 \%)$ \\
\hline $\begin{array}{l}\text { 4-6 times } \\
\text { per week }\end{array}$ & $36(20.8 \%)$ & $79(45.7 \%)$ & $0(0 \%)$ & $19(11.0 \%)$ & $52(30.1 \%)$ & $34(19.7 \%)$ & $42(24.3 \%)$ & $16(9.2 \%)$ \\
\hline Never & $6(3.4 \%)$ & $3(1.7 \%)$ & $47(27.2 \%)$ & $14(8.00 \%)$ & $5(2.9 \%)$ & $6(3.4 \%)$ & $2(1.2 \%)$ & $10(5.8 \%)$ \\
\hline
\end{tabular}

Legumes, E.g. (beans; lentils, chickpeas); Green leafy vegetables, E.g. (broccoli; lettuce); Citrus fruits, E.g. (oranges; grapefruit); Wholegrain, E.g. (whole wheat bread) 
Table 4 shows the most prevalent daily symptom of anemia among respondents was hair falls (13.9\%) while the least was Inflammatory or soreness of the tongue. Fatigue, difficulty concentrating in about one-third of study population was experienced 1-2 times weekly.

Table4. The symptoms that respondents might have (Symptoms Checker)

\begin{tabular}{llllll}
\hline $\begin{array}{l}\text { Experience any of the following } \\
\text { symptoms }\end{array}$ & Daily & $\begin{array}{l}\mathbf{4 - 6} \text { times a } \\
\text { week }\end{array}$ & $\begin{array}{l}\mathbf{2 - 3} \text { times a } \\
\text { week }\end{array}$ & $\begin{array}{l}\mathbf{1 - 2} \text { times a } \\
\text { week }\end{array}$ & Never \\
\hline Fatigue & $14(8.1 \%)$ & $6(3.5 \%)$ & $29(16.8 \%)$ & $57(32.9 \%)$ & $67(38.7 \%)$ \\
Dizziness & $4(2.3 \%)$ & $12(6.9 \%)$ & $8(4.6 \%)$ & $37(21.4 \%)$ & $112(64.7 \%)$ \\
Shortness of Breath & $5(2.9 \%)$ & $5(2.9 \%)$ & $5(2.9 \%)$ & $34(19.6 \%)$ & $124(71.7 \%)$ \\
Pale Skin & $3(1.7 \%)$ & $2(1.2 \%)$ & $7(4.0 \%)$ & $22(12.7 \%)$ & $139(80.3 \%)$ \\
Brittle Nails & $3(1.7 \%)$ & $1(0.6 \%)$ & $3(1.7 \%)$ & $11(6.4 \%)$ & $155(89.6 \%)$ \\
Cracks of the mouse corners & $1(0.6 \%)$ & $4(2.3 \%)$ & $7(4.0 \%)$ & $14(8.1 \%)$ & $147(85.0 \%)$ \\
Unusual rapid heart beat & $4(2.3 \%)$ & $10(5.8 \%)$ & $11(6.4 \%)$ & $34(19.7 \%)$ & $114(65.9 \%)$ \\
Leg cramps or numbness & $4(2.3 \%)$ & $4(2.3 \%)$ & $13(7.5 \%)$ & $29(16.8 \%)$ & $123(71.1 \%)$ \\
Headache & $7(4.0 \%)$ & $4(2.3 \%)$ & $11(6.4 \%)$ & $48(27.7 \%)$ & $103(59.5 \%)$ \\
Difficulty concentrating & $11(6.4 \%)$ & $11(6.4 \%)$ & $11(6.4 \%)$ & $60(34.7 \%)$ & $80(46.3 \%)$ \\
Chest Pain & 0 & $2(1.2 \%)$ & $3(1.7 \%)$ & $20(11.6 \%)$ & $148(85.5 \%)$ \\
Cold hands and feet & $12(6.9 \%)$ & $7(4.0 \%)$ & $10(5.8 \%)$ & $28(16.2 \%)$ & $116(67.1 \%)$ \\
Poor appetite & $7(4.0 \%)$ & $11(6.4 \%)$ & $15(8.7 \%)$ & $29(16.7 \%)$ & $111(64.2 \%)$ \\
Inflammatory or soreness of your tongue & 0 & 0 & $2(1.2 \%)$ & $8(4.6 \%)$ & $163(94.2 \%)$ \\
Feeling Itchy & $2(1.2 \%)$ & $2(1.2 \%)$ & $12(6.9 \%)$ & $11(6.4 \%)$ & $146(84.4 \%)$ \\
Hair Fails & $24(13.9 \%)$ & $9(5.2 \%)$ & $12(6.9 \%)$ & $13(7.5 \%)$ & $115(66.5 \%)$ \\
\hline
\end{tabular}

\section{Discussion}

The findings of this study showed no association between dietary, gynecological, drug history, and anemia in male and female participants, which is inconsistent with most other studies in the US that suggested positive associations $(26,27)$. In the present study, dietary items such as red meat, vegetables, cereals, and fruits had no association with anemia, which does not match with the outcomes of other studies in the middle east as well $(28,29)$.The reasons for these inconsistencies may be attributed to the fact that our population was healthy youngsters who are mainly active and their economic status good and more and non-alcoholic . Also, the low percentage of anemia among our population diluted the association between anemia and other factors. The results showed that our population eating variety of meat and vegetables which is excellent as well as their weights show that they are well nourished. They also not frequently taking medications and the majority do not have diseases associated with anemia. The inclusion criteria also of 18 to 28 restricted the inclusion of older participants who might show more relevant findings.

Meat is the primary source of haem iron ( $10 \%-20 \%$ of iron), while vegetables, fruits, and cereals are the main source of non-haem iron (80\%-90\%). The absorption of non-haem iron is affected by the iron level in the body and the equilibrium status between enhancers and inhibitors to a higher degree versus haem iron (30). Meat and vitamin $C$ are the chief boosters of non-haem iron absorption $(8,30,31)$.
Our study revealed that the frequency of drinking juices or eating citrus fruits that contain vitamin $\mathrm{C}$ was not correlated with the risk of having anemia, which is also dissimilar as compared with most existing studies $(29,32)$. Vitamin $C$ is a potent enhancer of the absorption of iron from non-meat sources (30).

Tea, coffee, and cocoa contain iron absorption inhibitors, and their inhibitory effect has been reported by many studies (32, 33). However, the current study showed no statistically significant relationship between the intake of these drinks and having anemia. This is possible because the difference is tiny, and larger study sample sizes are required for detection.

Heavy menstruation leads to severe blood loss, which is a primary risk factor for the onset of anemia among females of childbearing ages (33). Our results indicated there was no statistically significant association between heavy menstruation and anemia; however, the number of females with heavy menstrual periods in this study was not enough to accurately confirm or disprove such an association (2.9\%).

Calcium intake and the use of intrauterine devices and contraceptive pills have been correlated with depleted iron reserves $(28,33)$. However, these factors were not examined in this study.

Risk factors for anemia caused by pregnancy, as reported by the literature are multifaceted (33). The demand for iron is increased by pregnancy, which requires such for the development of the placenta and the fetus in addition to addressing the blood loss at delivery. 
Additionally, when the time between pregnancies is less than two years, the risk of developing anemia is augmented (30). Despite these prior findings, however, the current study did not consider the association between anemia and pregnancy, birth interval, or iron administration during pregnancy or after delivery because the study sample was mainly composed of students, where pregnancy and its complications were not the focus of the authors.

One important finding is the high risk of anemia in patients using NSAIDs; however, this relationship was not statistically significant $(p<0.05)$. Other studies have previously reported that NSAIDs can cause anemia among users because of the medications' ability to cause gastrointestinal bleeding (27).

Separately, a family history of anemia was associated with anemia but not in a statistically significant manner. Dietary lifestyle is generally inherited within families, which thus plays a vital role in the onset of anemia in multiple family members. Hence, the investigation of dietary lifestyles within families is of value in defining the enhancers and inhibitors of iron absorption. For this reason, nutritional habits were investigated in the present study.

In addition, the most prevalent daily symptoms of anemia were hair loss followed by fatigue and cold hands and feet. These symptoms affected both males and females on a regular basis, although this fact might be due to their nature as general symptoms for other diseases as well. Long-term complications of anemia such as brittle nails and cracked skin in certain areas were almost never reported, possibly because of the age range of the participants, who were all between 18 and 28 years old; the chronic symptoms of anemia require more time to develop.

\section{Limitations}

Around $30 \%$ of women filling out the questionnaire refused to provide a blood sample for hemoglobin analysis, mainly due to the fear of getting a needle prick. Information bias may also be present, as past family and personal history of IDA were based on participants' verbal responses. The strength of this study is the test for hemoglobin to make sure of the anemia diagnosis which reduces the recall bias.

\section{Conclusion}

The most specific risk for anemia among Saudi individuals of college and young professional ages (18-28 years old) was the female gender. The dietary lifestyle, heavy menstruation, pregnancy, and NSAID use were important risk factors; however, they were not statistically significant. Public awareness about anemia is important including regarding improving dietary behaviors and taking iron supplementation for prevention in high-risk people. Additionally, NSAIDs should be used with caution.

\section{Recommendations}

Further in-depth investigation of the etiological factors of iron deficiency and malnutrition is warranted. Suitable nutrition education and iron supplementation programs should be enacted. Health programs targeting public awareness to improve the health and nutritional status of university students should be implemented. School health and nutrition programs should be directed toward both school students and their parents.

\section{References}

1. Organization $\mathrm{WH}$. The global prevalence of anaemia in 2011. 2015.

2. Al Sulayyim HJ, Al Omari A, Badri M. An assessment for diagnostic and therapeutic modalities for management of pediatric Iron defficiency Anemia in Saudi Arabia: a crossectional study. BMC pediatrics. 2019;19(1):314.

3. Al Hawsawi ZM, Al-Rehali SA, Mahros AM, Al-Sisi AM, Al-Harbi KD, Yousef AM. High prevalence of iron deficiency anemia in infants attending a well-baby clinic in northwestern Saudi Arabia. Saudi medical journal. 2015;36(9):1067.

4. Gautam S, Min H, Kim H, Jeong H-S. Determining factors for the prevalence of anemia in women of reproductive age in Nepal: Evidence from recent national survey data. PloS one. 2019;14(6):e0218288.

5. Ali SA, Abbasi Z, Feroz A, Hambidge KM, Krebs NF, Westcott JE, et al. Factors associated with anemia among women of the reproductive age group in Thatta district: study protocol. Reproductive health. 2019;16(1):34.

6. Organization WH. Iron deficiency anemia. assessment, prevention, and control. A guide for programme managers. 2001:47-62.

7. Hens SM, Godde K, Macak KM. Iron deficiency anemia, population health and frailty in a modern Portuguese skeletal sample. PloS one. 2019;14(3):e0213369.

8. WHO U. Guidelines for the control of iron deficiency in countries of the Eastern Mediterranean. Middle East, and North Africa Report of a joint WHO/UNICEF consultation Iran: WHO-EM/NUT/177, E/G/1196. 1995.

9. Black RE, Allen LH, Bhutta ZA, Caulfield LE, De Onis $M$, Ezzati $M$, et al. Maternal and child undernutrition: global and regional exposures and health consequences. The lancet. 2008;371(9608):243-60.

10. Xiong X, Buekens $P$, Alexander S, Demianczuk N, Wollast $E$. Anemia during pregnancy and birth outcome: a meta-analysis. American journal of perinatology. 2000;17(03):137-46. 
11. Lartey A. Maternal and child nutrition in SubSaharan Africa: challenges and interventions. Proceedings of the Nutrition Society. 2008;67(1):105-8.

12. Allen LH. Biological mechanisms that might underlie iron's effects on fetal growth and preterm birth. The Journal of nutrition. 2001;131(2):581S-9S.

13. Zhang $Q$, Ananth CV, Rhoads GG, Li Z. The impact of maternal anemia on perinatal mortality: a population-based, prospective cohort study in China. Annals of Epidemiology. 2009;19(11):793-9.

14. Brabin BJ, Premji Z, Verhoeff F. An analysis of anemia and child mortality. The Journal of nutrition. 2001;131(2):636S-48S.

15. Stoltzfus RJ, Mullany L, Black RE. Iron deficiency anaemia. Comparative quantification of health risks: global and regional burden of disease attributable to selected major risk factors. 2004;1:163-209.

16. Scholl TO. Iron status during pregnancy: setting the stage for mother and infant-. The American journal of clinical nutrition. 2005;81(5):1218S-22S.

17. Killip S, Bennett JM, Chambers MD. Iron deficiency anemia. Am Fam Physician. 2007;75(5):671-8.

18. Al-Sayes F, Gari M, Qusti S, Bagatian N, Abuzenadah A. Prevalence of iron deficiency and iron deficiency anemia among females at university stage. Journal of Medical Laboratory and Diagnosis. 2011;2(1):5-11.

19. Elzahrani S. Prevalence of iron deficiency anemia among pregnant women attending antenatal clinics at Al-Hada Hospital. Canadian Journal on Medicine. 2012;3(1):10-4.

20. Mahfouz AA, El-Said MM, Alakija W, Badawi IA, AlErian R, Moneim MA. Anemia among pregnant women in the Asir region, Saudi Arabia: an epidemiologic study. Southeast Asian journal of tropical medicine and public health. 1994;25(1):84-7.

21. Al-Quaiz JM. Iron deficiency anemia. A study of risk factors. Saudi medical journal. 2001;22(6):490-6.

22. Short MW, Domagalski JE. Iron deficiency anemia: evaluation and management. American family physician. 2013;87(2).
23. Baker RD, Greer FR. Clinical Report-Diagnosis and prevention of iron deficiency and iron-deficiency anemia in infants and young children (0-3 years of age). Pediatrics. 2010:peds. 2010-576.

24. Harper JL, Conrad M, Besa E, Sacher R, Schick P, Talavera F. Iron deficiency anemia. Türkiye Klinikleri J Pediatr Sci 2009; 5: 6. 2014;14.

25. Benoist Bd, McLean E, Egll I, Cogswell M. Worldwide prevalence of anaemia 1993-2005: WHO global database on anaemia. Worldwide prevalence of anaemia 1993-2005: WHO global database on anaemia. 2008.

26. Tatala S, Svanberg U, Mduma BJTAjocn. Low dietary iron availability is a major cause of anemia: a nutrition survey in the Lindi District of Tanzania. 1998;68(1):171-8.

27. ahay R, Scott BJG. Iron deficiency anaemia--how far to investigate? 1993;34(10):1427-8.

28. Galan $P$, Yoon $H$, Preziosi P, Viteri F, Valeix P, Fieux B, et al. Determining factors in the iron status of adult women in the SU. VI. MAX study. 1998;52(6):383.

29. Craig WJ. Iron status of vegetarians. The American journal of clinical nutrition. 1994;59(5):1233S-7S.

30. Stoltzfus RJ, Dreyfuss ML. Guidelines for the use of iron supplements to prevent and treat iron deficiency anemia: Ilsi Press Washington, DC; 1998.

31. Verster A. Guidelines for the control of iron deficiency in countries of the Eastern Mediterranean, Middle East and North Africa. 1996.

32. Tseng $M$, Chakraborty $H$, Robinson DT, Mendez $M$, Kohlmeier L. Adjustment of iron intake for dietary enhancers and inhibitors in population studies: bioavailable iron in rural and urban residing Russian women and children. The Journal of nutrition. 1997;127(8):1456-68.

33. Control CfD, Prevention. Recommendations to prevent and control iron deficiency in the United States. MMWR. 1998; 47 (RR-3): 1-36. 2006. 